\title{
Investigation of anxiety sensitivity levels of cancer patients in terms of COVID-19 vaccine: a cross-sectional study
}

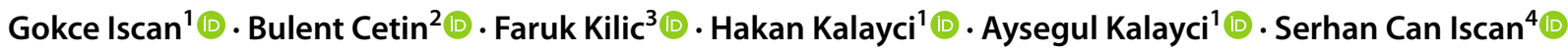

Received: 7 October 2021 / Accepted: 7 December 2021 / Published online: 24 January 2022

(c) The Author(s), under exclusive licence to Springer-Verlag GmbH Germany, part of Springer Nature 2021

\begin{abstract}
Introduction Our study's purpose was to investigate the viewpoints of cancer patients who had not yet been vaccinated. Cancer patients usually cannot get every vaccine because their immunity is low. For this reason, we aimed to detect their anxiety and curiosity for new vaccines for a new disease.

Methods The goal of this descriptive cross-sectional study was to investigate cancer patients' perceptions of COVID vaccination. Over 18 years of age who have not yet been vaccinated for COVID-19 and who agreed to participate were included in the study. We applied three questionnaires between May and June 2021, one of them was prepared by us; the other two questionnaires were The State-Trait Anxiety Inventory (STAI) form and Anxiety Sensitivity index to a total of 497 participants. Chi-square, Spearmen correlation test, and multivariable multinomial logistic regression tests were used when comparing. Results Our participants' ages were between 21 and 88, with a mean age of 61.38 (SD=11.68), 48.6\% ( $n=251)$ of the participants were female. We discovered that $79.1 \%(n=408)$ of respondents were not afraid of getting the COVID-19 vaccine. $27.7 \%(n=143)$ of these patients were concerned about the COVID-19 vaccine's adverse effects, and $24.2 \%(n=125)$ were afraid of its side effects with their treatments. $91.1 \%(n=470)$ of the patients did not know which vaccine they would have and the type of the vaccine. Since the anxiety level is generally higher in women, anxiety scores were also higher in cancers seen in women, such as breast and ovarian cancer. Of course, in parallel with this, anxiety scores were lower in prostate cancers. Special patient groups should not be neglected during this vaccine season, and their concerns should be addressed. When a new vaccine is found, it can have long-term effects, which should not be ignored.
\end{abstract}

Keywords Cancer $\cdot$ COVID-19 $\cdot$ Vaccination $\cdot$ Anxiety sensitivity $\cdot$ Anxiety

\section{Background}

The novel coronavirus, even described as SARS-Cov-2 or COVID-19, has emerged as a global health threat. The World Health Organization (WHO) announced a coronavirus disease 2019 (COVID-19) pandemic on March 11, 2020 , and the scale of the outbreak has only grown since

Gokce Iscan

dr_gokcedilek@yahoo.com

1 Department of Family Medicine, Suleyman Demirel University School of Medicine, Isparta, Turkey

2 Department of Oncology, Suleyman Demirel University, Isparta, Turkey

3 Department of Psychiatry, Suleyman Demirel University, Isparta, Turkey

4 Isparta City Hospital, Clinic of Gynecologic Oncology, Isparta, Turkey then [1]. Looking at May 8, according to the World health organization (WHO) data, there are more than 156 million definite cases and more than 3 million people who died due to COVID-19 in the world [2]. Although COVID-19 preventive behaviors such as wearing a mask and social distancing effectively prevent the spread of the virus, it has been understood that the long-term control of the COVID-19 pandemic will only be possible with the development of the appropriate vaccine [3].

It is believed that patients with chronic diseases are more likely to develop viral infection complications [4]. Patients with cancer had a higher risk of extreme events (intensive care unit admission, invasive ventilation, or death) than patients without cancer, according to a newly reported Chinese cohort (39\% vs. $8 \%, p=0.0003$ ) [5]. Compared to the general population, cancer patients had a double higher risk of COVID-19 infection in a study of 1.524 cancer patients [6]. Because of regular care and evaluation in the hospital, 
cancer patients are at risk of contracting COVID-19, and their immunity has been suppressed due to chemotherapy and radiotherapy. On the other hand, cancer patients need continuous monitoring and medical tests or treatments, whereas COVID-19 exposures can be hazardous and even fatal. Understanding the characteristics of cancer patients infected with the novel coronavirus, overcoming diagnostic and therapeutic barriers, and implementing guidelines to protect this vulnerable population from disease progression caused by test and treatment delays, as well as virus contamination, are all being pursued. Patients with cancer are considered a high-priority subgroup for COVID-19 vaccination due to the seriousness of the disease and the increased risk of death. The "American Association for Cancer Research (AACR)," the "American Society of Clinical Oncology (ASCO)," and the "Association of American Cancer Institutes (AACI)" have called on the "Centers for Disease Control and Prevention (CDC)" to make COVID-19 vaccination a top priority for cancer patients [7]. The "COVID-19 Vaccination Advisory Committee of the European Society for Medical Oncology (ESMO)," the "Society for Immunotherapy of Cancer (SITC)," and the "National Comprehensive Cancer Network (NCCN)" have issued tentative guidelines promoting vaccination in all cancer patients, including those on active treatment $[8,9]$.

Vaccines (also called immunizations or vaccinations) help a person's immune system recognize and protect the body against certain infections. They are usually not prescribed during chemo or radiation treatments, with the flu shot being the only exception. Because vaccines require an immune system response to function, which you do not receive during cancer treatment [10], it is now available to help protect against COVID-19 with vaccines. There are three types of vaccines that can be used. Messenger RNA (mRNA) is a type of genetic material found in the Pfizer-BioNTech and Moderna vaccines. Following vaccination, mRNA reaches the body's cells and instructs them to replicate the COVID19 virus's "spike" protein (the protein that usually helps the virus infect human cells). These vaccines do not cause illness, but they train the immune system to fight the infection in the future if the body is exposed to it. The Johnson \& Johnson (Janssen) vaccine contains an adenovirus (a form of the virus that is not the same as the coronavirus that causes COVID-19) that has been genetically modified to produce the gene for the COVID-19 virus' spike protein. As the adenovirus infects cells in the body, this gene instructs the cells to make spike protein copies. If the body is exposed to the COVID-19 virus again, the immune system will recognize and attack it. Since the adenovirus in this vaccine has been altered to no longer replicate in the body, it is not a live virus (nor can it cause disease). CoronaVac/Sinovac vaccines contain an inactivated virus that does not cause illness but produces an immune response (inactive vaccines). All four vaccines have been shown to reduce the risk of contracting COVID-19 substantially. If you are infected with COVID-19, they have also been shown to be very effective at lowering the risk of developing a severe illness, being hospitalized, or dying from it [11].

Anxiety is described as a feeling of unease, worry, or fear about a current or potential situation. Anxiety is a common concern in patients who have been diagnosed with cancer. Cancer patients, their families, and caregivers can experience fear and anxiety at various times during treatment and recovery [12]. It is essential to consider anxiety and take action to mitigate or prevent it from worsening.

Cancer patients' fear, whose diagnosis and treatment process is quite weary, increases with every new need. While COVID-19 and its vaccines created general uneasiness even in the average population, so in this study, it was aimed to determine the anxiety sensitivity of cancer patients and their immediate and continuous anxiety levels at the decision stage regarding COVID-19 vaccines.

\section{Methods}

\section{Research design}

We applied three questionnaires prepared by us; the other two were The State-Trait Anxiety Inventory (STAI) form and Anxiety Sensitivity index. The research was carried out at the Suleyman Demirel University in Isparta in May-June 2021, Turkey.

\section{Ethical consideration}

The study was authorized by the researchers' Suleyman Demirel University School of Medicine Ethical Committee with a decision no 10/186 and dated 26.04.2021 and approval. The Republic of Turkey Ministery of Health Scientific Research Platform provided the data for the study (form number 2021-04-05T15 54 30).

\section{Study population}

Patients who applied to the Suleyman Demirel University Oncology outpatient clinic between May and June 2021, who had not yet been vaccinated against COVID-19, were included in the study. The following are the requirements for inclusion: non-selected patients who were older than 18 years old, had a type of cancer, had completed the questionnaires adequately, and gave written informed consent to participate in the study. All of the patients who applied had a previous cancer diagnosis and were followed up here $(n=516)$. Volunteering was used as a criterion for inclusion in the study: incomplete questionnaires and the participants 
who had a psychiatric disorder diagnosis $(n=19)$ before were not considered. The questionnaire was administered to all patients face-to-face to 497 patients with consecutive sampling. With $G^{*}$ Power [13], a power of 0.95 with a medium effect size ( $\mathrm{f} 2=0.30$ ) and a significance of $=0.05$, and the sample size was found 488 .

\section{Data collection tools}

We employed a four-part questionnaire for this study. The first form consisted of sociodemographic questions, the second and third part was Spielberger State-Trait Anxiety Inventory questionnaires, and the last part was Anxiety Sensitivity Index-3.

\section{Form for collecting sociodemographic data}

The first 15 questions are the questions we prepared ourselves to learn the demographic and descriptive characteristics of the participants like age, gender, year of study, type of cancer, and type of cure. We made a reliability analysis to these questions, and the Cronbach alpha was found to be 0.91 .

\section{Spielberger State-Trait Anxiety Inventory}

Forty-item State-Trait Anxiety Inventory (STAI), both state (STAI-S), and trait anxiety (STAI-T) forms were used to examine anxiety symptoms in this questionnaire [13]. The STAI. with the STAI-S subscale measuring anxiety at the time of scoring is the gold standard for measuring anxiety and stress [14]. The items are added together per scale and converted into scores ranging from 20 to 80 . STAI-S and STAI-T both have 20 items with four-point Likert scales on each. Thus, scores range from 20 to 80 , with 20 representing a moderate amount of anxiety and 80 indicating a high level of anxiety. Anxiety symptoms have been linked to a score of 40 or above $[15,16]$. The scale's adaptation to Turkish validity and reliability studies was carried out by Öner and Le Comte (1983). Alpha reliability was between 0.83 and 0.87 , test-retest, reliability ranges between 0.71 and 0.86 , and item reliability varies between 0.34 and $0.72[17,18]$.

\section{Anxiety Sensitivity Index-3}

The Anxiety Sensitivity Index-3 is an 18-item self-report designed to gauge concern about anxiety-related symptoms' potential harmful repercussions. Some objects from the original ASI are included in the scale. The overall score is calculated by summing the responses on a 5-point Likert scale ranging from 0 (very little) to 4 (very much). The possible range of points for a Likert style evaluation is 0 to 72 . Physical concerns, cognitive concerns, and social concerns are the three subscales of the ASI-3. The ASI-3 has previously been shown to have good psychometric qualities as a reliable evaluation of anxiety sensitivity, with acceptable to good internal consistency for the total score and each subscale $[19,20]$. The Turkish adaptation study did not calculate the cut-off score, and high scores indicate increased anxiety sensitivity. Turkish Cronbach's alpha values were in the validity and reliability study, for the physical, social, and cognitive sub-dimensions, $0.89,0.82,0.88$, and 0.93 for the whole scale, respectively [21].

\section{Statistical analyses}

The age, gender, type of cancer, treatment, educational background, and chronic condition of each participant were all considered in the demographic analysis. Metrics from scales were translated to $\mathrm{z}$ scores and reverse-scaled, resulting in positive numbers as the most significant possible scores for all measurements. Categorical variables were described as numbers and percentages. In contrast, continuous variables were represented as the mean and standard deviation in a normal distribution or median and interquartile range in the case of a skewed distribution.

The chi-squared test also analyzed categorical variables. A value of $p<0.05$ was examined significantly. Spearman correlation was used to look for relevant relationships between different evaluation instruments. The connection of sociodemographic, cancer, and COVID-19-related factors with general attitude toward vaccination and refusal or uncertainty regarding COVID-19 vaccination was investigated using a multivariable multinomial logistic regression model. A "positive" attitude was defined as a reference category in the model, and "negative" and "neutral" attitudes were compared with it.

Socioeconomic status, marital status, type of cancer, treatment, smoking, chronicle disease, and educational background were all used as predictors in these studies. SPSS $®$ software was used for statistical analysis.

\section{Results}

\section{Study population}

A total of 516 people responded to the survey, with 497 of them being included in the study because 19 of these participants were previously diagnosed with a psychiatric illness. Our participants ranged from 21 to 88 years old, with a mean age of 61.38 years $(\mathrm{SD}=11.68) .48 .6 \%(n=251)$ of all participants were female; $51.4 \%(n=261)$ of them were male. The majority of the respondents (42.4\%) lived in a city, while $25.1 \%$ lived in villages. A majority of those who 
took part had primary education (73\%), were housewives (42.9\%), and were married (42.9\%). When evaluated according to their smoking status, $6.4 \%(n=33)$ of the participants were smoking, 56.8\% $(n=293)$ did not, and 36.8\% $(n=190)$ had quit.

Breast cancer was diagnosed in the majority of responders (25.7\%), followed by colon-rectum cancer (14.6\%), lung cancer (14.3\%), and gastric cancer (6.7\%), 51.2\% of the participants had at least one ailment, with cardiovascular disease being the most frequent.

When we examined the questions in the survey part of our study, where we evaluated the fear and knowledge of the COVID vaccine, it was analyzed that $79.6 \%(n=359)$ of the participants were afraid of being COVID. $12.2 \%(n=73)$ of the participants were fearful of being vaccinated against COVID and $8.7 \%(n=45)$ of them were indecisive. While $74 \%$ of the participants thought that the COVID vaccine would be effective. $91.1 \%(n=470)$ of the participants stated that they had no idea about the vaccine to be made. It should also be noted that $38.9 \%(n=201)$ of the participants indicated that they were afraid of side effects with the treatments they received. Table 1 shows the sociodemographic characteristics of the study population in detail.

\section{General attitudes and opinions about COVID-19 and COVID-19 vaccination}

Participants were asked to rate many statements on a Likert scale to gauge their general view of COVID and COVID vaccination (Table 2).

When we examined these questions according to gender, we saw that those who participated in the questions were more women, and those who disagreed were men except for questions 1.10.11. This shows that the men who participated in our study are more courageous about COVID-19.

We decided to dig deeper into the responses of patients who objected to the SARS-CoV-2 vaccine to understand their viewpoints on immunizations better. We asked about attitudes toward COVID-19 immunizations in the survey's final section. We discovered that $79.1 \%$ of respondents were not afraid of getting the COVID-19 vaccine. None of the participants had already been vaccinated against COVID19 at the time of the study. A majority of this population's respondents were concerned about the COVID-19 vaccine's adverse effects $(27.7 \%)$ and its side effects with their treatments $(24.2 \%)$. Most of the patients did not know which vaccine they would have and the type of the vaccine (91.1\%). Furthermore, nearly $20 \%$ of participants were concerned about adverse vaccination effects. $14.9 \%$ were afraid that the vaccine would cause disease composition, and $16.5 \%$ would advance their disease (see Table 2).

We built, first, a multivariable multinomial logistic regression model to find characteristics that predict afraid
Table 1 Sociodemographic characteristics of the study population

\begin{tabular}{|c|c|c|}
\hline Gender & $n$ & $\%$ \\
\hline Female & 251 & 48.6 \\
\hline Male & 265 & 51.4 \\
\hline \multicolumn{3}{|l|}{ Living place } \\
\hline Town & 130 & 25.2 \\
\hline District & 167 & 32.4 \\
\hline City & 219 & 42.4 \\
\hline \multicolumn{3}{|l|}{ Marital status } \\
\hline Single & 18 & 3.5 \\
\hline Married & 434 & 84.1 \\
\hline Divorced & 64 & 12.4 \\
\hline \multicolumn{3}{|l|}{ Education } \\
\hline No reading no writing & 37 & 7.2 \\
\hline Primary education & 377 & 73.0 \\
\hline High school & 63 & 12.2 \\
\hline University & 39 & 7.6 \\
\hline \multicolumn{3}{|l|}{ Smoking } \\
\hline Yes & 33 & 6.4 \\
\hline No & 293 & 56.8 \\
\hline Quit & 190 & 36.8 \\
\hline \multicolumn{3}{|l|}{ Working status } \\
\hline Student & 3 & 0.6 \\
\hline Housewife & 222 & 43.0 \\
\hline Unemployed & 21 & 4.1 \\
\hline Employed & 43 & 8.3 \\
\hline Retired & 227 & 44.0 \\
\hline \multicolumn{3}{|l|}{ Monthly income } \\
\hline No income & 222 & 43.0 \\
\hline Minimum wage & 13 & 2.5 \\
\hline Twice the minimum wage & 236 & 45.7 \\
\hline $\begin{array}{l}\text { Three times the minimum wage and } \\
\text { more }\end{array}$ & 40 & 7.8 \\
\hline
\end{tabular}

of vaccination or indecisive attitudes (model goodness-of-fit Cox and Snell pseudo- $R$ square 0.118 , Pearson chi-square $p=0.205)$ about demographical values. The only significant factor was the family status $(p=0.005)$ in likelihood ratio testing. A second multivariable multinomial logistic regression model to find characteristics that predict afraid of vaccination or indecisive attitudes (model goodness-of-fit Cox and Snell pseudo- $R$ square 0.120 , Pearson chi-square $p=0.998$ ) about cancer type, current treatment, and stage of cancer and smoking. In this model, the only significant factor was smoking status $(p=0.028)$ (see Tables 3 and 4 ).

When we analyzed with Kruskal-Wallis, the patients who were not afraid of getting the COVID-19 vaccine, the State Anxiety Scale score was statistically different from those who were afraid or indecisive $(p=0.001 ; p=0.015)$. 
Table 2 Cancer patients' general opinions on COVID and COVID vaccinations

\begin{tabular}{|c|c|c|c|}
\hline \multirow[t]{2}{*}{ Question } & \multicolumn{3}{|c|}{ Answer $n(\%) n=497$} \\
\hline & $\begin{array}{l}\text { Agree (Lik- } \\
\text { ert Scale } \\
1-2)\end{array}$ & $\begin{array}{l}\text { Neither disagree nor } \\
\text { agree (Likert Scale } \\
\text { 3) }\end{array}$ & $\begin{array}{l}\text { Disagree } \\
\text { (Likert Scale } \\
4-5)\end{array}$ \\
\hline 1. I'm afraid of being a COVID-19 patient & $359(69.6)$ & $8(1.6)$ & $149(28.9)$ \\
\hline 2. I'm afraid of getting the COVID-19 vaccine & $63(12.2)$ & $45(8.7)$ & $408(79.1)$ \\
\hline 3. I'm afraid that the COVID-19 vaccine will cause the disease & $77(14.9)$ & $52(10.1)$ & $387(75)$ \\
\hline 4. I'm afraid the COVID-19 vaccine will have side effects & $103(20)$ & $71(13.8)$ & $342(66.3)$ \\
\hline $\begin{array}{l}\text { 5. The COVID-19 vaccine is new, and I do not believe that this vaccine will protect against } \\
\text { the disease }\end{array}$ & $59(11.4)$ & $75(14.5)$ & $382(74)$ \\
\hline 6. COVID-19 is not a bad disease, as mentioned. I do not see the need to be vaccinated & $37(7.2)$ & $74(14.3)$ & $405(78.5)$ \\
\hline 7. I'm afraid the COVID-19 vaccine will advance my disease & $85(16.5)$ & $88(17.1)$ & $343(66.5)$ \\
\hline 8. I'm afraid that the COVID-19 vaccine will have side effects with the treatments I take & $125(24.2)$ & $76(14.7)$ & $315(61)$ \\
\hline 9. I am afraid that the vaccine will cause serious illness because I have low immunity & $143(27.7)$ & $64(12.4)$ & $309(59.9)$ \\
\hline 10. I don't think I need to be vaccinated because I have COVID-19 & $41(7.9)$ & $73(14.1)$ & $402(77.9)$ \\
\hline 11. I have no idea what type of vaccine I'll get & $470(91.1)$ & $19(3.7)$ & $27(5.2)$ \\
\hline
\end{tabular}

Table 3 Using multivariable multinomial logistic regression, predictors of negative, and neutral attitudes about immunization. The most important aspects are highlighted in bold

\begin{tabular}{|c|c|c|c|c|}
\hline \multirow[t]{2}{*}{ Factor } & \multicolumn{2}{|c|}{ Afraid of COVID vaccination } & \multicolumn{2}{|c|}{$\begin{array}{l}\text { Indecisive of COVID } \\
\text { vaccination }\end{array}$} \\
\hline & OR & $95 \% \mathrm{CI}$ & OR & $95 \% \mathrm{CI}$ \\
\hline Female (ref. male) & 2.958 & $0.957-9.140$ & 0.879 & $0.176-4.384$ \\
\hline \multicolumn{5}{|c|}{ Education (ref. illiterate) } \\
\hline Primary & 0.570 & $0.228-1.428$ & 1.171 & $0.349-3.927$ \\
\hline Secondary & 0.891 & $0.204-3.897$ & NA & NA \\
\hline High school & 0.789 & $0.226-2.747$ & 1.048 & $0.210-5.242$ \\
\hline University & 0.749 & $0.173-3.238$ & 1.832 & $0.323-10.40$ \\
\hline \multicolumn{5}{|c|}{ Place of living (ref. village) } \\
\hline Town & 0.815 & $0.377-1.760$ & 0.415 & $0.178-0.966$ \\
\hline City & 0.998 & $0.477-2.085$ & 0.514 & $0.233-1.134$ \\
\hline \multicolumn{5}{|c|}{ Marital status (ref. single) } \\
\hline Widow & NA & NA & 0.641 & $0.098-4.204$ \\
\hline Married & $44,359,785$ & $\begin{array}{r}11,553,049- \\
170,326,514\end{array}$ & 1.188 & $0.151-9.344$ \\
\hline \multicolumn{5}{|c|}{ Occupational status (ref. retired) } \\
\hline Student & NA & NA & NA & NA \\
\hline Housewife & 1.071 & $0.318-3.609$ & 1.685 & $0.311-9.131$ \\
\hline Unemployed & 1.199 & $0.225-6.378$ & 1.227 & $0.281-5.360$ \\
\hline Employed & 1.974 & $0.679-5.736$ & 0.534 & $0.105-2.728$ \\
\hline \multicolumn{5}{|c|}{ Family status (ref. alone) } \\
\hline Other & 1.311 & $0.320-5.364$ & 0.830 & $0.186-3.698$ \\
\hline Extended family & 0.512 & $0.076-3.436$ & 0.408 & $0.059-2.822$ \\
\hline Nuclear family & 1.183 & $0.218-6.412$ & 0.773 & $0.125-4.772$ \\
\hline With wife/husband & 0.420 & $0.079-2.222$ & 0.209 & $0.035-1.239$ \\
\hline
\end{tabular}

*Multivariable multinomial logistic regression

No statistically significant correlation was found between the Anxiety Sensitivity Index (ASI-3) and the STAI form scale scores $(r=0.041, p=0.358 ; \mathrm{r}=-0.081, p=0.067)$.
Table 4 Using multivariable multinomial logistic regression, predictors of negative, and neutral attitudes about immunization. The most important aspects are highlighted in bold

\begin{tabular}{|c|c|c|c|c|}
\hline \multirow[t]{2}{*}{ Factor } & \multicolumn{2}{|c|}{$\begin{array}{l}\text { Afraid of COVID } \\
\text { vaccination }\end{array}$} & \multicolumn{2}{|c|}{$\begin{array}{l}\text { Indecisive of } \\
\text { COVID vaccination }\end{array}$} \\
\hline & OR & $95 \%$ CI & OR & $95 \% \mathrm{CI}$ \\
\hline \multicolumn{5}{|l|}{ Cancer type (ref. other) } \\
\hline Lung cancer & 0.603 & $0.192-1.900$ & 1.815 & $0.431-7.652$ \\
\hline Breast cancer & 1.962 & $0.781-4.932$ & 3.317 & $0.851-12.92$ \\
\hline Colon-rectum cancer & 0.891 & $0.307-2.586$ & 2.287 & $0.575-9.107$ \\
\hline Ovarian cancer & 1.309 & $0.378-4.531$ & 3.794 & $0.768-18.73$ \\
\hline Gastric cancer & NA & NA & 5.450 & $1.054-28.16$ \\
\hline Prostate cancer & 0.659 & $0.133-3.256$ & 5.344 & $1.254-22.78$ \\
\hline \multicolumn{5}{|c|}{ Treatment (ref. no treatment) } \\
\hline Chemotherapy & 2.178 & $0.953-4.981$ & 1.797 & $0.730-4.420$ \\
\hline Targeted therapy & 1.827 & $0.568-5.876$ & 0.820 & $0.152-4.411$ \\
\hline Hormonal therapy & 1.204 & $0.399-3.631$ & 1.056 & $0.307-3.626$ \\
\hline Immunotherapy & NA & NA & NA & NA \\
\hline \multicolumn{5}{|c|}{ Smoking status (ref. no.) } \\
\hline Yes & 2.796 & $0.974-8.027$ & 4.973 & $1.564-15.81$ \\
\hline Quit & 0.685 & $0.302-1.556$ & 1.006 & $0.415-2.438$ \\
\hline
\end{tabular}

*Multivariable multinomial logistic regression

Women had considerably higher mean state anxiety $(p<0.01)$ and Anxiety Sensitivity Index-3 $(p=0.013)$ scores than men. According to marital Status and treatments, there was no statistically significant difference in the state $(p=0.107)$, trait anxiety levels $(p=0.107)$, and ASI-3 $(p=0.061)$ scores. When we examine the scores according to education, the STAI-S score average was the highest among 
Table 5 Spearmen correlation results between ASI-3, Strait, and Trait Anxiety Scores

\begin{tabular}{lllll}
\hline & & $\begin{array}{l}\text { Anxiety Sensitiv- } \\
\text { ity Index-3 }\end{array}$ & $\begin{array}{l}\text { State Anxiety } \\
\text { Score }\end{array}$ & $\begin{array}{l}\text { Trait } \\
\text { Anxiety } \\
\text { Score }\end{array}$ \\
\hline Spearman's rho & Anxiety Sensitivity Index & 1.000 & & \\
& Strait Anxiety Score & 0.041 & 1.000 & \\
& Trait Anxiety Score & -0.081 & $\mathbf{0 . 2 9 6}^{* *}$ & 1.000 \\
\hline
\end{tabular}

** Spearmen correlation is significant at the 0.01 level [2-tailed] illiterates $(p=0.035)$, while the ASI-3 score was the lowest among university graduates $(p<0.01)$. Unemployed patients have the lowest scores about STAI-S $(p<0.01)$, and ASI-3 scores of homemakers were statistically significantly high $(p=0.001)$. There was a significant difference in STAI-S scores between extended family and another living type. STAI-S scores were the highest $(p=0.005)$, and ASI-3 scores were the lowest in the extended family $(p<0.01)$. The cancer type in Breast and Ovarian Cancer patients had the highest; prostate cancer patients had the lowest STAI-S scores. This was statistically different from other types of cancer $(p=0.004)$. When we analyze the scores according to income level, the anxiety levels of people working below the minimum wage were found to be significantly higher $(p<0.01)$, while the sensitivity to anxieties was found to be substantially higher in those earning three times the minimum wage or higher $(p=0.022)$ (Tables 5 and 6$)$.

\section{Discussion}

Except for our work, another study looked into cancer patients' fears about vaccination, the usage of programs to aid their education, and the need of all country units cooperating (22. 23). Physicians and care providers can better address patients' needs and promote and encourage COVID19 vaccines by studying their perceptions of the vaccine. There were various barriers to successful immunization programs among cancer patients before the SARS-CoV-2 epidemic [24]. Vaccination rates among cancer patients remained low, despite clear advice to protect patients taking anti-cancer medication against preventable diseases such as influenza [25, 26, 27]. Furthermore, most patients actively seek information on the vaccine and place a high value on their physicians' advice in this area. Both of the studies mentioned above corroborate this finding, emphasizing the importance of clinical oncologists in promoting vaccine acceptance among patients [22,23]. Other vaccines, such as influenza, have indicated professionals' support in patients' decisions [28, 29]. According to data from influenza studies, a patient's provider's suggestion leads to a sevenfold higher likelihood of vaccination [27]. On the other hand, our survey revealed the grim reality of the COVID-19 pandemic; clinical oncologists with limited time and resources frequently fail to address patients' requirements for COVID-19 vaccine information. $91.1 \%$ of the patients participating in our study did not know the type of vaccine. However, this can partly be explained because the mRNA vaccine had just started to be implemented in our country when we conducted the study. The questionnaire was applied before the doctor's meeting when people came to get vaccinated. Oncological patients in Turkey were just included a new type of vaccine in the national vaccination program at the time of the survey. The latter emphasizes the physician's critical role in patient education and the formation of vaccination attitudes. A history of influenza vaccination appears to be a reliable predictor of COVID-19 vaccine uptake [23], as evidenced by studies in both cancer patients and the general population [30, 31].

The primary concerns expressed by cancer patients with negative attitudes about the vaccination, according to our poll, were fear of side effects, causing serious illness, increasing the severity of the disease, and a lack of knowledge. Previous polls of cancer patients' attitudes toward the influenza vaccine indicated very identical results [32]. It is worth noting that all of the worries mentioned above can be effectively handled through educational techniques. Research evaluating the impact of a SARS-CoV-2 webinar on cancer patients recently confirmed this [22]. Because past influenza vaccines influenced the adoption of the COVID-19 vaccine, these educational efforts may help shape long-term vaccination attitudes and lead to higher vaccination rates for future infectious diseases.

Although a moderate correlation was found between the STAI-T/S and ASI-3 scales in the study of Sandin et al., no correlation was found in our research $(\mathrm{r}=-0.049$, $p=0.269 / r=0.078, p=0.079$ respectively) [33]. Only there was a weak correlation between STAI-T and STAI-S, and it was statistically different $(r=0.296, p<0.01)$.

When we analyzed the STAI scale results according to demographic data, it was found to be higher in women, illiterate people, extended families, in people diagnosed with breast and ovarian cancer, low-income, and patients living in villages. Chen et al. found that STAI scores did not alter significantly according to marital status. Patients with a high school diploma showed significantly greater anxiety levels 
Table 6 STAI-S, STAI-T, and ASI-3 scores based on the participants' sociodemographic variables

\begin{tabular}{|c|c|c|c|c|c|c|}
\hline Sociodemographic characteristics & $\begin{array}{l}\text { STAI-T } \\
\text { Mean } \pm \text { Sd }\end{array}$ & $p$ & $\begin{array}{l}\text { STAI-S } \\
\text { Mean } \pm \text { Sd }\end{array}$ & $p$ & $\begin{array}{l}\text { ADI-3 } \\
\text { Mean } \pm \text { Sd }\end{array}$ & $p$ \\
\hline \multicolumn{7}{|l|}{ Gender } \\
\hline Female & $32.43 \pm 0.25$ & 0.521 & $41.44 \pm 0.36$ & $<0.01$ & $22.31 \pm 0.84$ & 0.013 \\
\hline Male & $32.13 \pm 0.25$ & & $39.02 \pm 0.32$ & & $19.52 \pm 0.76$ & \\
\hline \multicolumn{7}{|l|}{ Place of living } \\
\hline Village & $32.75 \pm 0.35$ & 0.404 & $41.30 \pm 0.45$ & 0.006 & $19.11 \pm 1.24$ & 0.007 \\
\hline Town & $31.98 \pm 0.31$ & & $40.25 \pm 0.45$ & & $23.06 \pm 0.98$ & \\
\hline City & $32.21 \pm 0.27$ & & $39.51 \pm 0.37$ & & $20.26 \pm 0.82$ & \\
\hline \multicolumn{7}{|l|}{ Marital status } \\
\hline Married & $32.33 \pm 0.19$ & 0.494 & $40.05 \pm 0.27$ & 0.107 & $21.35 \pm 0.61$ & 0.061 \\
\hline Single & $32.88 \pm 0.70$ & & $39.33 \pm 1.35$ & & $21.55 \pm 2.67$ & \\
\hline Widow & $31.72 \pm 0.52$ & & $41.42 \pm 0.65$ & & $17.51 \pm 1.71$ & \\
\hline \multicolumn{7}{|l|}{ Education } \\
\hline Illiterate & $32.51 \pm 0.74$ & 0.128 & $41.49 \pm 0.89$ & 0.035 & $20.41 \pm 2.25$ & $<0.01$ \\
\hline Primary & $31.99 \pm 0.22$ & & $40.54 \pm 0.30$ & & $22.76 \pm 0.68$ & \\
\hline Secondary & $33.20 \pm 0.75$ & & $39.32 \pm 1.01$ & & $13.52 \pm 2.14$ & \\
\hline High school & $33.14 \pm 0.40$ & & $39.00 \pm 0.63$ & & $17.17 \pm 1.54$ & \\
\hline University & $32.56 \pm 0.59$ & & $38.36 \pm 0.83$ & & $15.05 \pm 1.87$ & \\
\hline \multicolumn{7}{|l|}{ Occupational status } \\
\hline Student & $34.00 \pm 0.58$ & 0.068 & $40.00 \pm 2.00$ & $<0.01$ & $15.67 \pm 8.41$ & 0.001 \\
\hline Housewife & $32.37 \pm 0.27$ & & $41.49 \pm 0.38$ & & $23.36 \pm 0.88$ & \\
\hline Unemployed & $32.24 \pm 0.75$ & & $38.33 \pm 1.07$ & & $21.95 \pm 3.41$ & \\
\hline Employed & $33.35 \pm 0.51$ & & $40.19 \pm 0.81$ & & $15.67 \pm 1.91$ & \\
\hline Retired & $31.95 \pm 0.27$ & & $39.11 \pm 0.35$ & & $19.41 \pm 0.79$ & \\
\hline \multicolumn{7}{|l|}{ Monthly income } \\
\hline No income & $32.54 \pm 0.26$ & & $41.45 \pm 0.37$ & & $22.87 \pm 0.91$ & \\
\hline Under minimum wage & $31.23 \pm 1.71$ & 0.067 & $42.69 \pm 1.64$ & $<0.01$ & $22.15 \pm 3.77$ & 0.022 \\
\hline Minimum wage & $31.88 \pm 0.26$ & & $39.18 \pm 0.34$ & & $19.53 \pm 0.75$ & \\
\hline Minimum wage $\times 2$ & $33.17 \pm 0.58$ & & $38.47 \pm 0.82$ & & $17.05 \pm 2.32$ & \\
\hline Minimum wage $\times 3$ and more & $34.40 \pm 1.50$ & & $39.80 \pm 1.56$ & & $23.20 \pm 8.06$ & \\
\hline \multicolumn{7}{|l|}{ Family status } \\
\hline Alone & $31.54 \pm 0.66$ & 0.005 & $40.00 \pm 0.89$ & 0.197 & $18.39 \pm 2.28$ & $<0.01$ \\
\hline With wife/husband & $32.04 \pm 0.24$ & & $39.79 \pm 0.32$ & & $22.77 \pm 0.67$ & \\
\hline Nuclear family & $33.25 \pm 0.33$ & & $40.90 \pm 0.51$ & & $18.00 \pm 1.36$ & \\
\hline Extended family & $33.28 \pm 0.65$ & & $40.67 \pm 0.88$ & & $13.85 \pm 3.00$ & \\
\hline Other & $31.35 \pm 0.60$ & & $41.14 \pm 0.88$ & & $19.59 \pm 2.11$ & \\
\hline \multicolumn{7}{|l|}{ Cancer type } \\
\hline Lung cancer & $31.86 \pm 0.44$ & 0.148 & $38.80 \pm 0.66$ & 0.004 & $18.33 \pm 1.40$ & 0.445 \\
\hline Breast cancer & $32.61 \pm 0.33$ & & $41.37 \pm 0.48$ & & $20.80 \pm 1.11$ & \\
\hline Colon-rectum cancer & $32.58 \pm 0.50$ & & $40.78 \pm 0.66$ & & $22.35 \pm 1.61$ & \\
\hline Ovarian cancer & $32.50 \pm 0.69$ & & $41.40 \pm 0.96$ & & $24.40 \pm 2.60$ & \\
\hline Prostate cancer & $30.69 \pm 0.68$ & & $37.94 \pm 0.76$ & & $19.12 \pm 1.87$ & \\
\hline Gastric cancer & $31.86 \pm 0.65$ & & $39.28 \pm 0.86$ & & $22.00 \pm 2.17$ & \\
\hline Other & $32.39 \pm 0.36$ & & $39.97 \pm 0.46$ & & $20.96 \pm 1.11$ & \\
\hline \multicolumn{7}{|l|}{ Treatment } \\
\hline Chemotherapy & $32.27 \pm 0.28$ & 0.659 & $39.75 \pm 0.39$ & 0.461 & $19.66 \pm 0.86$ & 0.067 \\
\hline Targeted therapy & $31.93 \pm 0.58$ & & $40.49 \pm 0.79$ & & $23.88 \pm 1.90$ & \\
\hline Hormonal therapy & $32.55 \pm 0.38$ & & $40.64 \pm 0.56$ & & $19.68 \pm 1.45$ & \\
\hline Immunotherapy & $30.40 \pm 1.50$ & & $38.80 \pm 1.98$ & & $31.60 \pm 4.84$ & \\
\hline No treatment & $32.27 \pm 0.31$ & & $40.53 \pm 0.42$ & & $21.79 \pm 0.98$ & \\
\hline
\end{tabular}

*Kruskal-Wallis 
than those with the other patients who had lower education as our study [34]. Since the anxiety level is generally higher in women, anxiety scores were also higher in cancers seen in women, such as breast and ovarian cancer. Of course, in parallel with this, anxiety scores were lower in prostate cancers. It was thought that the high STAI-T scores in extended families during the pandemic period were due to contamination risks as a result of crowded life, and the low ASI-3 score was thought to be due to the situation of getting used to this stress.

A few limitations should be considered when evaluating the findings of this study. The bulk of the patients were graduates from primary school who lived in cities and were retired.

\section{Conclusions}

Overall, we found that people have positive opinions concerning immunizations, and most of them are not afraid of getting vaccinated against COVID-19 in our study. Notably, a large percentage of patients believe they are underinformed on the type of vaccine, efficacy, and adverse effects. This is a significant element in vaccination apprehension. Given that COVID-19 and cancer are the most severe risks to human health today, additional efforts should be made to educate patients about immunization. Several parts should be involved, including physicians of all specialties, nurses, patient organizations, stakeholders, and the media. It is worth noting that COVID-19 immunization in cancer patients not only protects them from infection and serious consequences but also allows them to continue and finish their oncological therapy as planned, resulting in superior long-term outcomes.

The first reactions to anything new can be considered normal, to break the vaccine resistance here, the known side effects of the vaccine, the way of action should be explained in detail, and people's concerns should be tried to be resolved. It should not be forgotten that this microorganism is also new and incomprehensible to science. Finally, we would like to point out that a generally positive attitude toward vaccination predicts a greater likelihood of COVID19 vaccine uptake. If a new vaccination against another potentially life-threatening disease becomes available, this finding could have long-term ramifications.

Author contribution Bulent Cetin: conceptualization, supervision, project administration; Faruk Kilic: project administration, supervision; Hakan Kalayci: investigation; Aysegul Kalayci: investigation. All authors contributed, read, and approved the final manuscript.

Data Availability Not applicable.
Code availability Not applicable.

\section{Declarations}

Ethics approval The questionnaires were administered via direct interactions with patients after approval by the ethics committees.

Approval numbers of ethics committees for implementing research Suleyman Demirel University Faculty of Medicine ethics committee approval number 186 / 53914. Turkish Ministry of Health ethics committee approval number GÖKÇE İŞCAN-2021-0405T15_54_30.

Consent to participate Informed consent was obtained from all individual participants included in the study.

Consent for publication Not applicable.

Conflict of interest The authors declare no competing interests.

\section{References}

1. Han G. Zhou YHJJomv. Possibly critical role of wearing masks in general population in controlling COVID-19. 2020.

2. Organisation WH. WHO Coronavirus (Covid-19) Dashboard 2021 [Available from: https://covid19.who.int/.

3. Cohen MS. Corey L. Combination prevention for COVID-19. American Association for the Advancement of Science; 2020.

4. Haybar H. Kazemnia K. Rahim F. Underlying chronic disease and COVID-19 infection: a state-of-the-art review. Jundishapur Journal of Chronic Disease Care. 2020;9(2).

5. Liang W, Guan W, Chen R, Wang W, Li J, Xu K et al (2020) Cancer patients in SARS-CoV-2 infection: a nationwide analysis in China. Lancet Oncol 21(3):335-337

6. Yu J. Ouyang W. Chua ML. Xie C. SARS-CoV-2 transmission in cancer patients of a tertiary hospital in Wuhan. MedRxiv. 2020.

7. Ribas A, Sengupta R, Locke T, Zaidi SK, Campbell KM, Carethers JM et al (2021) Priority COVID-19 vaccination for patients with cancer while vaccine supply is limited. Cancer Discov 11(2):233-236

8. Cancer SfIo. (SITC) Statement on SARS-CoV-2 Vaccination and Cancer Immunotherapy 2020 [Available from: https://www.sitca ncer.org/aboutsitc/press-releases/2020/sitc-statement-sars-cov-2vaccination-cancer-immunotherapy.

9. Network NCC. COVID-19 Vaccination and cancer patients 2021 [Available from: https://www.nccn.org/covid-19.

10. Society AC. COVID-19 Vaccines in People with Cancer 2021 [Available from: https://www.cancer.org/treatment/treatmentsand-side-effects/physical-side-effects/low-blood-counts/infec tions/covid-19-vaccines-in-people-with-cancer.html

11. Desai A, Gainor JF, Hegde A, Schram AM, Curigliano G, Pal S et al (2021) COVID-19 vaccine guidance for patients with cancer participating in oncology clinical trials. Nat Rev Clin Oncol 18(5):313-319

12. Faul F. Erdfelder E. Buchner A. Lang A-G. G* Power Version 3.1. 7 [computer software]. Uiversität Kiel. Germany. 2013.

13. Speilberger C. Manual for the State Trait Anxiety Inventory (Form Y) Consulting Psychologists Press: Palo Alto. CA; 1983.

14. Moerman N, van Dam FS, Muller MJ, Oosting H (1996) The Amsterdam preoperative anxiety and information scale (APAIS). Anesth Analg 82(3):445-451 
15. Tsuboi N, Ernandez T, Li X, Nishi H, Cullere X, Mekala D et al (2011) Regulation of human neutrophil Fc $\gamma$ receptor IIa by C5a receptor promotes inflammatory arthritis in mice. Arthritis Rheum 63(2):467-478

16. Jiang H. Lu N. Chen K. Yao L. Li K. Zhang J. et al. Predicting brain age of healthy adults based on structural MRI parcellation using convolutional neural networks. Frontiers in neurology. 2020;10:1346.

17. Öner N. Le Compte A. Süreksiz durumluk/sürekli kaygı envanteri el kitabı (2. Bask1). İstanbul: Boğaziçi Üniversitesi. 1998.

18. Aydemir Ö. Koroglu E. Clinical scales used in psychiatry. Ankara: Hekimler Yayin Birligi. 2000:33-41.

19. Taylor S, Zvolensky MJ, Cox BJ, Deacon B, Heimberg RG, Ledley DR et al (2007) Robust dimensions of anxiety sensitivity: development and initial validation of the Anxiety Sensitivity Index-3. Psychol Assess 19(2):176

20. Peterson R. Reiss S. Anxiety sensitivity index: Lawrence Erlbaum Associates; 1992.

21. Mantar A. Anksiyete Duyarlılı̆̆ı İndeksi-3'ün Türkçe formunun geçerlik ve güvenilirlik çalışması: Dokuz Eylül Üniversitesi Tıp Fakültesi; 2008.

22. Kelkar AH. Blake JA. Cherabuddi K. Cornett H. McKee BL. Cogle CR. editors. Vaccine enthusiasm and hesitancy in cancer patients and the impact of a Webinar. Healthcare; 2021: Multidisciplinary Digital Publishing Institute.

23. Barrière $\mathrm{J}, \mathrm{Gal} \mathrm{J}$, Hoch $\mathrm{B}$, Cassuto $\mathrm{O}$, Leysalle A, Chamorey E et al (2021) Acceptance of SARS-CoV-2 vaccination among French patients with cancer: a cross-sectional survey. Ann Oncol 32(5):673-674

24. Ariza-Heredia EJ. Azzi J. Shah DP. Nesher L. Ghantoji SS. Michailidis L. et al. Influenza vaccination in patients with cancer: factors associated with vaccination practices for patients and their household members. infection control \& hospital epidemiology. 2015;36(10):1239-41.

25. Poeppl W, Lagler H, Raderer M, Sperr WR, Zielinski C, Herkner $H$ et al (2015) Influenza vaccination perception and coverage among patients with malignant disease. Vaccine 33(14):1682-1687

26. Loulergue P, Mir O, Alexandre J, Ropert S, Goldwasser F, Launay $\mathrm{O}$ (2008) Low influenza vaccination rate among patients receiving chemotherapy for cancer. Ann Oncol 19(9):1658
27. Vollaard A, Schreuder I, Slok-Raijmakers L, Opstelten W, Rimmelzwaan G, Gelderblom H (2017) Influenza vaccination in adult patients with solid tumours treated with chemotherapy. Eur J Cancer 76:134-143

28. Vinograd I, Baslo R, Eliakim-Raz N, Farbman L, Taha A, Sakhnini A et al (2014) Factors associated with influenza vaccination among adult cancer patients: a case-control study. Clin Microbiol Infect 20(9):899-905

29. Akin S. Dizdar O. Karakas Y. Ozisik L. Tanriover MD. Kamisli S. et al. Vaccination perception and attitudes among patients with cancer receiving chemotherapy. Annals of Oncology. 2016;27:vi514.

30. Paul E. Steptoe A. Fancourt D. Attitudes towards vaccines and intention to vaccinate against COVID-19: implications for public health communications. The Lancet Regional Health-Europe. 2021;1:100012.

31. Soares P, Rocha JV, Moniz M, Gama A, Laires PA, Pedro AR et al (2021) Factors associated with COVID-19 vaccine hesitancy. Vaccines 9(3):300

32. Urun Y, Akbulut H, Demirkazik A, Senler FC, Utkan G, Onur H et al (2013) Perception about influenza and pneumococcal vaccines and vaccination coverage among patients with malignancies and their family members. Age 57:18-90

33. Sandin B. Chorot P. McNally RJJBr. therapy. Anxiety sensitivity index: normative data and its differentiation from trait anxiety. 2001;39(2):213-9.

34. Chen L. Zhao H. Razin D. Song T. Wu Y. Ma X. et al. Anxiety levels during a second local COVID-19 pandemic breakout among quarantined people: a cross sectional survey in China. 2021;135:37-46.

Publisher's note Springer Nature remains neutral with regard to jurisdictional claims in published maps and institutional affiliations. 